\title{
Blinds Bluffing of Vision: Paul de Man on Text
}

\author{
Ali Jamalinesari \\ Department of English Language and Literature, Islamic Azad University, Ilam Branch, Ilam, Iran \\ E-mail: jamalinesari@yahoo.com
}

Received: 13-05-2014

doi:10.7575/aiac.ijalel.v.3n.6p.64
Accepted: 01-07-2014

Published: 01-11-2014

\begin{abstract}
Because of its figural or rhetorical component, language cannot be a reliable medium for stating truth. Rhetoric continually undermines the abstract systems of grammar and logic and any attempt to fix a connection between the book and the world is futile. Regarding the metaphoricity of language, this article tries to prove that how the critic's search for meaning is defied by the difference between what is meant and what is said which is a de Man's focal point. To have a correct misreading, we have to allow language express itself in its full multiplicity, taking as many possible significations as it can and as many various contradictory direction that it heads toward. There is no authoritative, authentic voice in a text. Each is as helpless and baseless as any other. The text dismantles itself. It annihilates the ground on which it stands.
\end{abstract}

Keywords: Paul de Man, Language, Figurality, Misreading, Unreadiblity, Deconstruction

\section{Introduction}

What is deconstruction? That is the question this article tries to deal with and at the same time shows that how the metonymic language is basically metaphoric and since any literary text is expressed via language, it is also deconstructed when its brick taken out. Deconstruction is a question no less important than Shakespeare's to be or not to be question, because in its narrower sense it is concerned with no less than the whole western culture and civilization and in its broader sense it covers the whole domain of existence. It questions the whole fabric of philosophy, religion, sets of values proposed by human beings, generation after generation and defended or attacked during the whole history of life on the earth; those sets of values for the preservation or annihilation of which there has been endless bloodshed, fidelity, treason, wickedness, etc. Deconstruction questions the interests and whatever enters that domain acquires a political aspect, interferes with the working of power and starts a defensive or aggressive dialogue with power structure. It has won itself the friendship of a good many all over the world as well as the hostility of no less a number.

Thus, it seems challenging enough to offer us the right to question it's whatness. We do have a right to ask: "what is deconstruction" which is followed by an enquiry into its true nature, since it has the power not only to change our outlook of the whole world and our view point of life but also our life itself. However, the success is exactly the failure since any such enquiry presupposes language and the important role it plays in clarifying the meanings of concepts and in determining the definitions of terms and in general, the communicative power it enjoys. And that is exactly what deconstruction seeks to refuse. Any such enquiry is mediated by language, it is done through language, it needs, first of all, a firm belief in the transparency of language, of the possibility of a unified, coherent meaning communicated through words and grammatical relations, and the immunity of language to paradoxical signification, while, the most important building block in the structure of deconstruction is its refusal to give language such a privilege. It refuses to admit to the communicative power of language. It asserts, above all, that any stretch of language produces unwanted paradoxes to disperse meaning, to do violence to any coherence and unity and consequently, to make it impossible to decide the exact meaning of any word.

Nicholas Royle (2000) in an article entitled "What is Deconstruction" grapples with the illusory nature of the task. His article takes the form of a formal letter he writes to those in charge of Chambers Dictionary. Praising their Painstaking work in their meticulous engagement with language and more exactly with definition of words, he quotes their definition of deconstruction which later on proves to be the loose brick he has found in the structure of the dictionary to make its whole fabric collapse. The definition reads:

Deconstruction. n. a method of critical analysis applied esp. to literary texts, which, questioning the ability of language to represent reality adequately asserts that no text can have a fixed and stable meaning and that readers must eradicate all philosophical or other assumption when approaching a text. (Royle 2000, p. 1)

To Royle, this definition seems "awful beyond words. It is so bad that [he] hardly know [s] where to begin to vent [his] lexicographical sadness and spleen."(ibid)

His irritation with Chambers Dictionary definition is rooted in that definition's invitation of the readers to "eradicate all philosophical and other assumptions"(ibid) while to him it is impossible, beyond imagination. Furthermore, that definition considers deconstruction as a method, while, it is wrong since the word "method carries connotations of a 
procedural form of judgment."(Beardsworth 1996, P. 4) A thinker with a method" Royle quotes Beardsworth "has already decided how to proceed."(ibid) Disappointed with this definition he looks for a new one. He finds it in the Oxford English Dictionary:

\section{Deconstruction [f.DE+CONSTRUCTION]}

a. The action of undoing the construction of a thing.

b. Phlios. and Lit. Theory. A strategy of critical analysis associated with the French philosopher Jacque Derrida, directed towards exposing unquestioned metaphysical assumption and internal contradictions in philosophical and literary language.(2000, p. 2)

This definition, Royle prefers to the previous one. It gives the older meaning of the word. It uses "strategy" instead of method. It does not limit deconstruction only to literary texts, but expands its domain to include philosophy as well. So far it is a better definition. However, it is lacking in many respects. Most important of all is that it concentrates on language. It also tends to take a text as a particular way of coming together of words as black marks on paper. On the contrary, Royle observes, deconstruction is not limited to literature or philosophy, it "has to do with identity and experience in general."(2000, p. 7) It does not focus on language or text in the narrower sense of these two words. It is not a "strategy" of reading texts in this sense. Text, as Bennington observes,

"Is in general any system of marks, traces, referrals... Perception is a text. Deconstruction does not have a place for language over here, and a world over there to which it refers. Elements in the language refer to one another for their identity, and refer to non-linguistic marks which difference refers in turn to their identity and difference. There is no essential difference between language and the world."(1989, p. 84)

Bennington here refers to Derrida's extension of difference among signifiers to signifieds as well. In this respect the world, its phenomena and objects are understood in linguistic terms. When discussing Derrida, this will be explored in more details. To return to our discussion, Royle quotes Derrida several times. Deconstruction according to Derrida is first and foremost inventive, otherwise, nothing at all. It is openness to the text, a readiness to follow its traces. That is why it is neither a method with defined procedural map, nor a strategy. It is:

"Neither a theory nor a philosophy. It is neither a school nor a method. It is not even a discourse, nor an act, nor a practice. It is what happen, what is happening today in what is called society, politics, diplomacy, economics, historical reality and so on and so forth."(Derrida 1990b, p. 85)

Royle himself ends up with a definition of deconstruction which seems odd at the beginning, but certainly, has to do with the complexities and oddities of it, suggesting how difficult a task it is to handle. It reads:

Deconstruction $\mathrm{n}$. not what you think: the experience of the impossible: what remains to be thought: a logic of destabilization always already on the move in "things themselves": what makes every identity at once itself and different from itself: a logic of spectrality: a theoretical and practical parasitism or virology: what is happening today in what is called society, politics, diplomacy, economics, historical reality, and so on: the opening of the future itself (2000, p. 11).

A text is thus, approached by a deconstructionist on the assumption that it yields to different interpretations. A text can be read again and again, each time offering a manning different from the previous time. The greatest joy of a text is its capability of submitting to contradictory interpretation. The critic traces the course of the text to find the loose brick in Millerian terms (1999) which ruins the whole building if it is taken out. To do so the critic may observe how the figurative meaning of the text opposes and undermines its literal meaning. This is a favorite way of Paul de Man's (1979) when reading a text. That is what we now turn to discuss.

\section{Paul de Man on Text}

\subsection{Blindness and Insight}

New Critics, de Man (1999) believes, set out quest in search of organic unity, but they were ignorant of the fact that their desire to reach unity was exactly what gave birth to a criticism of ambiguity and multiplicity of meaning. They attributed to the text what was nothing more than the illusory mental image of the critic. Any such enquiry presupposes language and the important role it plays in clarifying the meanings of concepts and in determining the definitions of terms and in general, the communicative power it enjoys. It is mediated by language, it is done through language, it needs, first of all, a firm belief in the transparency of language, of the possibility of a unified, coherent meaning communicated through words and grammatical relations, and the immunity of language to paradoxical signification, and that is exactly what deconstruction seeks to refuse. The most important building block in the structure of deconstruction is its refusal to give language such a privilege. It refuses to admit to the communicative power of language. It asserts, above all, that any stretch of language produces unwanted paradoxes to disperse meaning, to do violence to any coherence and unity and consequently, to make it impossible to decide the exact meaning of any word. Any stretch of language always produces a surplus of meaning which undermines the intention of the writer.

Although owed to a great extent to Derrida (1988), Paul de Man has had remarkable achievements in contributing to deconstruction. He has produced a lot of considerable critical works, but his two highly influential books Blindness and Insight (1999) and Allegories of Reading (1979) enjoy an unrivaled status. His paradoxical way of treatment suits his deconstructionist outlook. The main paradoxical idea he proposes in his Blindness and Insight (1999) is that critics 
achieve insight only through certain blindness. They adopt a method or theory, apply it to literary works and seek for the results they expect to obtain, but their task gives birth to results quite at odds with what they set forth for. They have an intention to give expression to their ideas, they prepare for it, they plan, they structure their arguments in the direction of their intentions, but they always come out with the opposite. What they actually say is in sharp contrast to what they intended to say. For instance, the American New Critics announced the autonomy of the text, set forward to prove the autonomy and self - sufficiency of it by reading each text closely, paying close attention to details and trying to justify the relation each component part bore to the whole. Particularly, they concentrated on the Collerigean concept of organic unity. A poem was thought of as a living creature with no extra members, nor any missing parts. In its autonomy, it needed vitally its entire component parts arranged exactly the way they were, but nothing more. There was no element it needed which it did not have. There was a complicated network of relationships among the part. Each contributed to the whole and the functioning of all presented one and only one unified entity. That was what New Critic craved. They found in a text autonomous unity because they had a strong will to. Their strategy gave them the insight to find organic unity and autonomy, however, only at the cost of blindness to the warring forces, the opposing tendencies, the dissenting voices and the contradictory assertions. They emphasized unity but they faced multiplicity. The more they tried to clear a text from parasitical margins clinging to it and bringing into it something out of the unity domain or the domain of autonomy, the stronger the marginalized voices declared their right to be heard. They aimed in short at a criticism of unity, autonomy and wholeness, but they ended with "a criticism of ambiguity" to take a phrase from Paul de Man.

De Man (1999) believes that this insight - in - blindness is facilitated by an unconscious slide from one kind of unity to another. The unity which New Critics so frequently discover is not in the text but in the act of interpretation. Their desire for total understanding initiates the hermeneutic circle of interpretation. Each element in a text is understood in terms of the whole, and the whole is understood as a totality made up of all the elements. This interpretative movement is part of a complex process which produces literary form. Mistaking this circle of interpretation for the text's unity helps them sustain a blindness which produces insight into poetry's divided and multiple meanings (the elements themselves do not form a unity). Criticism must be ignorant of the insight it produces.

\subsection{Allegories of Readings}

If Derrida (1973) questions the distinction between speech and writing, the subordination of writing to speech and the superiority of speech with its claim to presence, Paul de Man does the same to the pair, philosophy and literature, taken illegitimately for a binary opposition. De Man (1979) does the same to literal and figurative language as well, the two binary oppositions bearing an affinity to one another. Philosophy distinguishes itself from literature and claims superiority to the latter through its ignorance of its literariness. Philosophy can be philosophical only when it shuns the yoke of figurality. It blames literature for its fictionlaity, imaginary nature and figurative language and claims itself a higher states by deny such accusations. Both de Man and Derrida question the distinction, prove philosophy to be contaminated with literature and literature haunted always by philosophy. Philosophy is as fictional, literary and figurative as literature is. It is governed by rhetoric. However, they refuse the formation of a new binary opposition: literature /philosophy, philosophy still remains as a distinct form of writing, but under erasure. Similarly, we discover that literal language is in fact figurative language whose figuration has been forgotten. Figurative language by definition is one that uses an element to represent another. 'The peach is coming' is figurative since it means the beautiful lady is coming, using one element to represent another. If that is the case literal language is a figurative as figurative language itself. To say plain literal 'the lady is coming ' does not purify language from its figurality, since in this case , as well, certain elements are used to represent others; the written marks "the lady" represent a woman out there and "is coming" arbitrarily stands for an action that lady does. De Man deconstructs the binary opposition 'literal/figurative' to question the distinction between philosophy and literature long held by Western civilization.

In his Allegories of Reading, de Man (1979) goes into details with what he had already begun in Blindness and Insight. $\mathrm{He}$ is here concerned with the theory of tropes, established and manipulated by rhetoricians in their treatises of rhetoric which means the art of persuasion. Tropes or figures of speech allow writers to say one thing but mean something else. It is possible to mention something to mean just part of it or to mention part of something and signify the whole (synecdoche), to utter a word and intend another with which it is one way or another related (metonymy) and to say one thing and mean something quite different, bearing no tangible relation or similarity (metaphor) and so on.

A trope de Man observes, pervades language exerting a force which destabelishes logic, and thereby denies the possibility of a straightforwardly literal or referential use of language. Here an example given by Selden and Widdoson is quoted "To the question 'tea or coffee?' I reply 'what's the difference?' my rhetorical question (meaning 'It makes no difference which I choose') contradicts the logic of my question's literal' meaning (what is the difference between tea and coffee?)"(Selden and Widdoson 1993, p. 151) Paul de Man rigorously illustrates that just as critical insight is obtained only at the cost of critical blindness, a stretch of language can be interpreted literally only if the rhetorical implications are suppressed. Language always produces some surplus of meaning impossible for the speaker or writer to control or prevent, giving rise to the possibility of contradictory meanings and dissenting voices. A text can offer a coherent meaning only when you suppress and ignore the various tell - tale signs scattered, all over the text, of multiplicity of meaning, lack of unity and impossibility of coherence. De Man grounds his theory in close readings of specific texts (Deconstructionists have always blamed New Critics close reading as not close enough to reveal inconsistencies) and considers that it is the effects of language and rhetoric that prevent a direct representation of the real. He follows Nietzsche in believing that language is essentially figurative and not referential or expressive. There is 
no original unrhetorical language. This means that reference is always contaminated with figurality.

These arguments are applicable to criticism itself as de Man (1979) does. Any piece of critical writings is a reading of a given literary work. Reading is mediated by language which is pervaded by literary devices or tropes (figures of speech). Therefore the figurative meaning that is the rhetorical aspect of language is always present, making any reading necessarily a misreading. Tropes inevitably intervene between critical and literary texts. Furthermore, any critical writing is allegorical in that it is a system of signs corresponding to another system of signs, namely the literary work, at a different level. If a literary work that tells the story of a fox helping a lion to kill and eat a sheep by playing a trick on the sheep, is interpreted as the story of a society where the ruling class employs the wit and intelligence of the theoreticians to exploit lower classes, we are facing an allegorical interpretation that presupposes two systems of signification at a certain distance from each other and corresponding to one another, one being the story, the characters and incidents taking place in it, the other, the interpretative reading with its events, people and intriguing actions. So, is the relation criticism bears to literature. They are two corresponding systems at a certain distance from one another, in de Manian terminology; it is a sequence of signs at a distance from another sequence of signs and seeks to stand in its place. Thus criticism, too, like philosophy is as textual and figurative as literature is.

De Man distinguishes two kinds of 'misreading': a correct one and an incorrect misreading. A correct misreading tries to include and not repress the inevitable misreading which all languages produce. At the center of this argument is the belief that literary texts are self-deconstructing. They simultaneously assert and deny the authority of their own rhetorical mode. A literary text makes the meaning it is struggling to produce and at the same time mingles it with its opposite tendencies. The text seems to be self - conscious in its own deconstruction and the deconstructionist has to do nothing except for following the natural course of the text to see how it has already undermined its own claims and dismantled itself.

\section{Conclusion}

Paul de Man (1999) focused on the paradoxical nature of critical insight. Such an insight he maintains, is possible only if we remain blind to some aspects of the text. Repressing those aspects always makes them more resistant and reluctant to leave the scene, so they reweave themselves into the critical reading and the critic unwantedly confesses to their existence. The critic strangely enough, always seems to say something different from what he means. De Man (1979) also concentrates on rhetoric and reason or the illegitimate distinction between literal and figurative language. Looking at critical practice as essentially allegorical in which one sequence of signs standing at a certain distance from another sequence corresponds to it, De Man obliterates the boundary between literature and criticism as he had done between philosophy and literature on a former occasion.

\section{References}

Beardsworth, R. (1996). Derrida \& the Political. Routledge.

Bennington, G. (1989). Deconstruction Is Not What You Think: And other Short Pieces and Interviews. Bennington Books.

Derrida, J. (1990b). Limited Inc., Paris.

Derrida, J. (1973). Speech and phenomena, Evanston, $3^{\text {rd }}$ edition.

Derrida, J. (1988). "Structure, Sign and Play in the Discourse of the Human Sciences in Lodge, D. Modern Criticism and Theory: A Reader, Longman.

De Man, P. (1979). Allegories of Reading: Figural Language in Rousseau, Nietzsche, Rilke, and Proust. New Haven, CT.

De Man, P. (1999). "The Resistance to Theory". Modern Criticism and Theory, ed. Lodge. Longman, pp.332-347.

Miller, J.H. (1999). "The Critic as Host ". Modern Cnticism and theory.ed. Lodge. Longman, PP.255-262.

Royle, N. (Ed.) (2000). Deconstruction: A user's Guide, New York.

Selden, R., Peter, S., and Widdoson. (1993). A Reader's Guide to Contemporary Literary Theory. New York, Harvester Wheatsheaf. 